\section{La fotografía argentina contemporánea. Una mirada hacia las comunidades indígenas}

Mercedes Pombo *

Resumen: Argentina se caracteriza por ser una nación heterogénea, con gran pluralidad de voces y culturas, dentro de las cuales se encuentra -relegada- la voz de las comunidades indígenas. Desde un comienzo los pueblos originarios han debido acomodarse a los usos y costumbres de los conquistadores, pero no por ello han perdido su propia identidad cultural, que aún perdura en sus ritos y maneras de encarar la vida.

Muchos artistas, a lo largo de la historia argentina, se han interesado por retratar estas costumbres y sus ideales. Pintores y fotógrafos han encarado este trabajo desde lo documental o artístico, cada uno desde enfoques y miradas diversas. Este interés por las comunidades indígenas dentro del campo artístico argentino continúa aún hoy presente.

Este artículo propone un acercamiento al trabajo de dos artistas que han sabido mostrar la vida de las comunidades indígenas en el norte del país desde una óptica de respeto y admiración hacia estas culturas. Se analiza el trabajo de dos fotógrafos argentinos contemporáneos: Guadalupe Miles y Sebastian Szyd, quienes -cada uno desde una estética muy particular y a través de sus series Chaco y América respectivamente- se han involucrado personalmente con estas culturas, formando parte de sus ritos y costumbres diarias.

El texto propone tomar distancia y analizar los discursos escondidos -atrapados en el silencio- que se encuentran tras las poses y miradas de los retratados en ambas series fotográficas; aprendiendo a valorar todo aquello que tienen para mostrar y que hacen a su identidad cultural.

Palabras clave: Argentina - Arte - contemporáneo - cosmovisión - cultura - diversidad Fotografía - identidad - igualdad - imaginario - indígenas - respeto.

[Resúmenes en inglés y portugués en la página 239]

${ }^{(*)}$ Licenciada en Artes Plásticas (UBA) y Fotógrafa. Se desempeña actualmente como docente en la Facultad de Diseño y Comunicación de la Universidad de Palermo y en la coordinación del área de Producción Teórica y Académica DC.

La pluralidad de voces fue una de las características más presentes en la construcción de las comunidades argentinas y latinoamericanas desde el período colonial. En Argentina, esta diversidad de miradas y pensamientos resultó determinante en la construcción de una nación heterogénea y mestiza. Pese al esfuerzo constante por imponer pautas, usos y costumbres de los conquistadores sobre los dominados -en una búsqueda constante por 
combatir la heterogeneidad- las comunidades indígenas han mantenido ciertas formas de vida y de pensamiento que se sostienen en el tiempo.

Frente a las presiones sociales y económicas presentes desde un comienzo, los pueblos indígenas han tenido que reacomodarse, replanteando sus costumbres, conceptos y símbolos, pero siempre manteniendo - pese a todo- su esencia e identidad cultural. Un punto fundamental que colaboró -y colabora hoy en día- para que cada una de estas culturas pueda tener su espacio y ser escuchada es -justamente- el rol de las imágenes artísticas, tanto desde la plástica como desde la fotografía.

El espacio que se le ofrece a las culturas precolombinas en el territorio argentino fue ganando interés y respeto con el paso de las décadas, de la mano de los pequeños (o grandes) aportes dados por las distintas disciplinas. Recién a fines del siglo XX la Constitución Nacional Argentina planteó una retribución a los pueblos indígenas que habitaban $-y$ habitan actualmente- diferentes zonas del territorio. Esta reforma del año 1994 significó el reconocimiento legal sobre estas comunidades, lo cual contribuyó a la validación de la preexistencia étnica y cultural de estos pueblos y el derecho a la propiedad comunitaria de sus tierras.

Desde el campo de las artes plásticas y la fotografía, este vínculo entre ambos mundos tan diferentes ha resultado interesante y atractivo para sus protagonistas. Retratar las costumbres, la apariencia física y la vestimenta de los indígenas fue -tanto para los europeos como para los primeros artistas argentinos- una atracción muy difícil de evitar. Sea desde una mirada romántica o más antropológica, tanto fotógrafos como pintores, se han ocupado desde los primeros contactos entre ambas culturas de mostrar este mundo como ícono "del otro" por excelencia. Estas imágenes muestran la exaltación de estos personajes como seres distintos en cuanto a ornamentación, formas de vida y cultura.

La mirada y concepción del indígena como un ser opuesto, distinto y amenazador para la sociedad occidental es tan fuerte, que aún hoy perdura en la mentalidad nacional. Tal como plantea Martínez Sarasola (2010) esa necesidad de acotar al indígena al lugar del diferente y exótico surge del imaginario colectivo de los argentinos. Se trata de una postura etnocéntrica y radical conectada con un concepto profundo que subyace en la mentalidad local, que es la discusión histórica acerca de la sobrevaloración de la civilización por sobre la barbarie. Tal como refieren Baigorria y Swarinsky (2002), esta dualidad ha quedado plasmada en la historia argentina con el libro Facundo de D. F. Sarmiento, que comenzó a circular en la sociedad en el año 1845 y que fue el responsable de poner en palabras y trazar claramente la barrera entre lo bárbaro y lo civilizado. Tanto el gaucho como el indio se presentaban como los responsables del estado de caos y vacío en que se encontraba el territorio. Sarmiento propone en su texto excluir y subordinar a estos pueblos indígenas y sus tradiciones culturales por considerarlos un obstáculo en el proceso modernizador de Argentina.

De todos modos, esta actitud de desvalorización al diferente es un rasgo común -y que se sostiene en el tiempo- en toda la sociedad occidental. En contraposición a esta postura, surgen -cada vez más- pensadores que pregonan una visión contraria. Es ejemplo de esto el escritor polaco Kapuscinski (2007) quien plantea la posibilidad de poder acercarse al otro -al diferente- sin preconceptos, y que esto sirve para comprender mejor el mundo, como un espejo en el cual cada uno puede verse reflejado. Este autor expone que en la 
historia de la humanidad han sido mucho los encuentros entre diferentes civilizaciones -Argentina y latinoamérica son algunos de los tantos casos-, donde las posibilidades de conexión se pueden dar, sea través del choque -sometimiento, dominación-; o desde el intercambio, en el cual subsiste el respeto y la humildad frente al otro. Las fotografías y obras plásticas de los indígenas en América del Sur han contribuido a despertar esta última forma de contacto. Poco a poco la mentalidad soberbia e irrespetuosa ha ido cambiando, dejando asomarse -casi a cuentagotas- un espacio abierto, que plantea nuevas relaciones con el otro, en este caso los pueblos originarios.

Este cambio de visión es muy paulatino, y gran parte ha quedado en manos de artistas plásticos y fotógrafos que presentan un enfoque diferente, alejado de la visión del indígena como un ser salvaje incurable, nómade y peligroso.

Uno de los primeros fotógrafos profesionales que se interesó por este universo local, fue el italiano Benito Panunzi, quien trabajó en Argentina entre 1865 y 1870 retratando gauchos de la Pampa e indios araucanos de la Patagonia Por primera vez en la historia de la fotografía en Argentina, Panunzi muestra retratos de nativos que no buscan apelar a una representación exótica del modelo sino que, por el contrario, lo humanizan.

Otro antecedente claro de este tipo de fotografías -en donde se destaca la búsqueda humana de los indígenas- es el trabajo de Martín Chambi, fotógrafo peruano de origen indio, quien en las primeras décadas del siglo XX se encargó de retratar sistemáticamente a sus ancestros y su mirada acerca del mundo que los rodeaba. Recorrió su país Perú -la tierra de los incas- en burro, con su cámara al hombro, descubriendo así los primeros asentamientos arqueológicos.

Algunos años más tarde, una de las fotógrafas referentes por excelencia del campo fotográfico argentino, Grete Stern, también se interesó por los indígenas, en este caso Chaco. Sus fotografías no solo plantean un tratamiento estético muy particular sino que también se desprende de ellas una mirada que se aleja de lo conocido hasta ese momento. Por un lado, estas imágenes muestran el universo cotidiano y el quehacer día a día de estas comunidades, lo cual resulta un documento invalorable para el campo de la antropología; pero también, su trabajo comienza a brindar al espectador un enfoque más humano y respetuoso de estas culturas.

Para comprender estas imágenes, tanto desde el espectador como del creador, es necesario adentrarse en ciertas cuestiones vinculadas al respeto por la diversidad y -tal como se planteaba anteriormente- poder situarse en el lugar del "otro".

Este tipo de trabajos fotográficos que buscan humanizar al indígena, intentando comprender sus pensamientos, ritos y formas de vida, surgen a partir de la segunda mitad del siglo XX, sea a través del ojo de artistas como Grete Stern antes mencionada, o también fotógrafas como la mexicana Graciela Iturbide, quien testimonia la vida de los indios de Juchitán, México planteando una mirada inclusiva, que muestra lo diferente con gran respeto y humildad, presentándose a sí misma como testigo de un universo de ritos, magia y divinidad.

La presente investigación propone indagar acerca de aquellos artistas que se ocupan actualmente de fotografiar a los indígenas argentinos desde una óptica de respeto y admiración por estas culturas. Artistas que utilizan esta herramienta como la propia extensión de su mirada, generando imágenes que traspasan lo antropológico o histórico. Se analiza 
el trabajo de dos fotógrafos contemporáneos: Guadalupe Miles y Sebastian Szyd, quienes basan su obra en la contemplación y entendimiento de estas comunidades. Sus fotografías reflejan el respeto a la diversidad.

Tanto Guadalupe Miles -con su ensayo fotográfico sobre el Chaco salteño- como Sebastián Szyd -y sus fotografías sobre Argentina y otros países latinoamericanos- plantean la posibilidad de integrar a estos pueblos relegados a la vida cotidiana del país, mostrando la unión entre lo estético, lo conceptual y afectivo.

El acercamiento a estas culturas por parte de ambos fotógrafos se aleja de la mirada documental, presentándose como una labor personal y expresiva ligada al lenguaje artístico. Miles y Szyd han realizado estas series fotográficas a lo largo de varios años, tomándose el tiempo para conocer y relacionarse con las comunidades retratadas. Tanto Guadalupe como Sebastián se involucraron personalmente con estas culturas, formando parte de sus ritos y costumbres diarias. Y esto se ve claramente en las imágenes, donde los personajes -sea posando hacia cámara o no- muestran actitudes naturales y relajadas. Es posible imaginar el vínculo personal entablado previamente entre el fotógrafo y quien posa ante el lente. Desde este concepto, ya es posible determinar de qué manera estos trabajos se alejan claramente del lugar de un 'otro' diferente y excéntrico.

A su vez, esta manera de encarar el trabajo fotográfico demuestra una profundidad en la mirada y la investigación visual, que lejos está de la sociedad actual, marcada por la fluidez y el cambio constante. Hoy -salvo contadas excepciones- el mundo se maneja, tal como lo plantea Bauman (2006) como un continuo zapping, donde tanto el espectador como el creador de imágenes saltan incansablemente de un concepto a otro. "La velocidad, y no la duración, es lo que importa" (Bauman, 2006, p.17). Esta modernidad líquida deviene en prácticas de consumo y creaciones artísticas signadas por la superficialidad y la inmediatez. Son las nuevas tecnologías un componente básico para este nuevo paradigma social; y junto con el boom de estas tecnologías, también cambian las formas de presentación y difusión del producto cultural, a la vez que cambian los actores.

Miles y Szyd -lejos de esta concepción- muestran otra manera de encarar la temática y serie fotográfica. Presentan fragmentos de la vida cotidiana de estos indígenas, quienes se saben observados, pero por un lente conocido y amigable. Miradas que los ubican en su propio contexto, bajo los valores y costumbres de sus ancestros, desde un lugar de respeto y admiración.

Guadalupe Miles se ocupa de retratar a la comunidad wichi, iowaja o choroté y nivaklé, poniendo el acento en lo estético y conceptual de la imagen, planteando un clara vinculación entre la persona a retratar y el paisaje. La serie fotográfica denominada Chaco surge luego de ocho años de investigación y trabajo, centrada en los nativos quienes conviven diariamente con la naturaleza y sus elementos más cercanos.

La comunidad wichi actual aún mantiene cierto estilo de vida heredada de sus comienzos en el territorio del Chaco salteño, en los siglos XVI y XVII. Se organiza en aldeas, constituidas por varias familias integradas por el padre, hijos y yernos. Las mujeres trabajan en el interior de la casa, centradas en la familia y sus necesidades. Las viviendas son precarias, 
algunas son de adobe, aunque la mayoría están construidas por cuatro palos horcones, con paredes revestidas por ramas. Viven actualmente en condiciones adversas, y casi olvidados por la sociedad. Su impronta es que estas culturas aún mantienen un vínculo muy fuerte con la naturaleza y la tierra, interpretada por ellos como un espacio libre y comunitario. En las imágenes de Miles, gran parte de esta realidad queda a la vista. En sus fotografías, muestra a los retratados conectados con una realidad diferente a la que están viviendo en ese momento frente a la cámara. Las posturas corporales y las miradas de los retratados traspasan el mero acto fotográfico. Es como si se pudiera percibir en esos ojos, en esas miradas una profunda conexión del retratado con la tierra. Miles propone un contacto extraño y particular entre el personaje frente a cámara y el espectador, en donde invita a quien observa a sentirse parte, pero a la vez lo deja al margen, proponiendo imaginar otra verdad muy diferente a la imagen presentada. Según palabras de Alonso "los wichís dejan de ser entidades que se miran para convertirse en individuos que se dejan ver, en su lugar y contexto (...)" (Alonso, 2005, s/p).

Por otra parte, Sebastian Szyd empieza su trabajo con los indígenas en el año 2003, cuando comienza a viajar sistemáticamente por Argentina y Latinoamérica, retratando la realidad de los pueblos originarios. Este trabajo desemboca en una serie fotográfica que se convierte en el libro América (2010). Este ensayo reúne imágenes de los pueblos andinos de Argentina, Chile, Perú y Bolivia que se caracterizan por indagar sobre los pobladores de estas regiones, su sincretismo y la capacidad de mantener intactas ciertas costumbres y creencias propias de su pasado. Son fotografías que acompañan la historia de pueblos callados, pero no sumisos. Culturas que sostienen cierta manera de ver el mundo, tan distinta a la occidental. En esta serie aparecen -solapados- cuestionamientos tales como las fronteras y los límites políticos, los espacios libres, la pertenencia de las tierras y sus ideas e ideales. Este artículo busca analizar y reflexionar acerca de cómo a través de las imágenes fotográficas los artistas seleccionados han conseguido representar al mundo indígena desde esta mirada respetuosa. Surgen variables ligadas a los pueblos originarios y sus costumbres que son utilizadas como eje estructural del trabajo para demostrar cómo estos fotógrafos respetan los hábitos y los pensamientos de estas comunidades. De esta forma, es posible plantear que ambos trabajos fotográficos contribuyen a fomentar en la sociedad actual una postura ligada al respeto y el entendimiento de estos pueblos; lo cual conduce a valorar la multiplicidad de voces que conviven en un mismo territorio.

Existen dos puntos claves ligados a estas comunidades -y que se encuentran alejados de los usos y costumbres actuales en Argentina- que actúan como disparadores de este texto. Este artículo propone concentrarse sobre estos dos aspectos fundamentales que sostienen a las culturas indígenas y que los fotógrafos antes mencionados han sabido mostrar en sus fotografías. A través de las imágenes y su manejo estético estos artistas invitan al espectador a escuchar a estas comunidades y darles la palabra para que aporten -desde su óptica- otra manera de ver el mundo. Los dos puntos a los que se hace mención son por un lado la relación del indígena con el paisaje y la naturaleza; y por el otro lado la visión de las prácticas ligadas a ritos y mitos, tan comunes en este tipo de comunidades. 


\section{El indígena y la naturaleza}

En las imágenes analizadas de ambos artistas, se puede descubrir una mirada profunda sobre el paisaje y la naturaleza, que deja ver aspectos de estas culturas que son intangibles, pero a la vez reales. El indígena se conecta con el cosmos y la tierra desde un lugar muy difícil de comprender para el hombre occidental.

Esta unión entre paisaje y personaje es posible relacionarlo con el pensamiento de las comunidades indígenas, donde cada uno es parte de un todo que va más allá de su propia individualidad. Tal como plantea Grünberg (2003) existe un denominador común en todos estos pueblos originarios, que es la estrecha relación que tienen con la naturaleza y la intensa y profunda importancia que le dan a esta vinculación. Se trata de un concepto que traspasa las fronteras de esta relación para ubicarse en un lugar profundo ligado a la trascendencia, el mito y la dimensión espiritual.

Las culturas originarias han desarrollado una visión totalizadora del mundo que se expresa en todos los aspectos de la vida. Todo en la vida indígena se ve y se vive con una perspectiva cosmológica. Y por eso el sentido de sacralidad y la voluntad de respetar el orden cósmico están presentes en todo momento, no sólo en los lugares o circunstancias especiales, ceremoniales o rituales, sino en la vida de todos los días.

Para el hombre indígena la vida cotidiana -e incluso el mismo cuerpo humano- son una réplica del funcionamiento del cosmos. Ambos planos, cotidianidad y cosmos, son reflejos el uno del otro. Lo que sucede a uno afecta e interviene en el otro (Llamazares y Sarazola, s/f).

De hecho, la relación que establecen las comunidades, tantos las andinas como las del litoral, con la agricultura también deja a la vista esta particular cosmovisión indígena. En palabras de García Salemi (2011) ellos mismos son parte integrante de la naturaleza, cobran sentido en función de ella y su adoración. Por ejemplo la sacralidad que toman algunas plantas en la cultura andina, tales como la papa o la coca. Es fundamental tener en cuenta en este punto la cultura del autoabastecimiento, donde estas comunidades han establecido la prioridad a su propia producción de alimentos y medicamentos.

Estos vínculos con lo natural y la tierra quedan expresados en las imágenes de ambos artistas. Tanto Miles -con sus retratos femeninos insertos en el barro- como Szyd a través del vínculo que establecen los retratados con el paisaje dejan a la vista esta relación afectiva y única que tienen los indígenas con su entorno. Incluso en las fiestas ligadas a la Pachamama y otras deidades de la naturaleza se refleja esta importancia y estilo de vida.

El tratamiento estético de las imágenes de Miles dejan entrever la trascendencia que tiene este vínculo para la comunidad wichi: el reflejo de la luz solar sobre los cuerpos, la calidez que emana de esa iluminación y las posturas de goce y placer de los retratados hablan acerca de esta profunda conexión con la tierra.

Gran parte de la serie Chaco apunta al contacto con la naturaleza: la tierra, el río, el cielo cobran un papel predominante como aquello que acompaña y enmarca a los retratados. Los 
cielos azules, la textura de la tierra o de las hojas y plantas debajo de la personas son una constante en las fotografías de esta serie. Y también resulta llamativo los cuerpos contoneados hacia el cielo: gran parte de estos retratados no miran a cámara ni al espectador; sino que se encuentran ligados a una fuerza mayor que se deja ver y sentir, ese vínculo potente entre el indígena y la naturaleza. Son fotografías que no poseen escenas construidas ni premeditadas. Simplemente es el retratado, la naturaleza y el ojo de la fotógrafa que se adentra en ese vínculo y lo captura [Ver Figuras 1 y 2 en Catálogo de Figuras en página 235].

La estética de Sebastián Szyd en su serie América-si bien dista mucho de la de Miles- tiene algunos puntos en común con ella. Uno es este vínculo fuerte entre indígenas y naturaleza, que se deja ver en las imágenes. En este caso la relación no es ideal ni romántica, pero sí mantiene ciertos rasgos bucólicos y nostálgicos, como si los retratados se conectaran a través de la mirada con el paisaje y su realidad. Una mirada que parece traspasar el tiempo actual y ubicarse en el contexto de la sociedad precolombina de otra época.

Al referirse a las imágenes y la comunicación, Barthes (2009) hace alusión a dos conceptos que sirven para reflexionar acerca de estas fotografías y su significado. El autor propone analizar las imágenes a partir de dos niveles de interpretación; por un lado la denotación que hace referencia a la temática expuesta y su significado literal; y por otro lado la connotación que se acerca a aquellos conceptos y significados profundos que el espectador debe decodificar en la búsqueda de sentido. Estos mensajes connotados pueden estar dados tanto desde la elección estética y técnica del artista, como desde la apelación temática y representativa. Al respecto Barthes plantea “(...) el código del sistema connotado está constituido visiblemente, bien por un sistema de símbolos universal, bien por una retórica de una época; en definitiva, por una reserva de estereotipos (esquemas, colores, grafismos, gestos, expresiones, agrupaciones de elementos)" (Barthes, 2009, p.14).

En el caso de Szyd la elección de fotografiar en blanco y negro le aporta una connotación ligada a la posibilidad de pensar estas imágenes sin la imposición de tiempos y espacios; a la vez que invita al espectador a sentir la nostalgia y el sentido de opresión que emerge de los retratados. Esto también queda en evidencia en el tipo de iluminación que recae sobre ellos: luces y sombras duras que los muestran en una búsqueda de conexión con la naturaleza y el pensamiento mítico. Son fotografías que invitan a reflexionar acerca de la cosmovisión indígena antes de la llegada de los españoles. Esos hombres mirando hacia el horizonte se posicionan en un espacio atemporal, donde la naturaleza cobra otro sentido, como un símbolo de pertenencia y lucha.

En el caso de Miles, las fotografías son en color, en su mayoría signadas por una luz cálida y difusa, con gran nitidez y detalles en las líneas y contornos; apelando a una estética más cercana al lenguaje publicitario que al documental (Alonso, 2005).

\section{Mitos y ritos}

Los mitos son relatos que se construyen para captar y comprender la realidad circundante. Son historias anónimas ancestrales y narradas oralmente de una generación a otra. "El mito es un relato (mito-narración) pero también se lo concibe como un complejo de 
creencias (mito-creencia), como una forma de captar y expresar un tipo específico de realidad (...)" (López Austin, 1998, p. 45). En ellas quedan expuestas parte de las creencias y filosofía de cada cultura.

Tal como plantea Levi Strauss (2000) los mitos tienen la naturaleza de símbolo que, por poseer cierto grado de convencionalidad, son productos sociales. El autor reconoce que un mito tiene su origen en la conciencia de un individuo en particular, pero al convertirse en tal a partir de la trasmisión oral y colectiva se transforma en un conjunto de necesidades y creencias compartidas; que unen en el pensamiento y el sentimiento a una comunidad en particular.

Por otra parte Jung (Olavarría, 1990) plantea a los mitos como símbolos en tanto que comunican más de lo que la historia en sí relata. De allí su postura y creencia de que una manera de conocer el inconsciente de cada cultura consiste en analizar sus mitos.

A su vez, los ritos aparecen acompañando estos mitos como una instancia básica para sus creencias y para sostener sus ideas. Se trata del momento de la celebración de los mitos, en donde se dan a conocer y reactualizan. Eliade (1994) plantea que el mito es el arquetipo del ritual: “(...) no se puede cumplir un ritual si no se conoce el 'origen'; es decir, el mito que cuenta cómo ha sido efectuado la primera vez” (Eliade, 1994, p. 23). Para este autor, no sólo los rituales tienen su modelo mítico, sino que cualquier acción humana adquiere su eficacia en la medida que repite exactamente una acción llevada a cabo en el comienzo de los tiempos por un dios, un héroe o un antepasado.

En las imágenes de Guadalupe Miles, esta idea de ritos indígenas queda al descubierto en varias ocasiones, pero de una manera solapada; invitando al espectador a imaginar lo que sucede o sucedió a través de la puesta en escena de objetos o recortes de la realidad que sugieren un universo de mitos alejados de la concepción occidental. Esto se vislumbra en varias de las fotografías de la serie Chaco, por ejemplo una imagen sobre un manojo de hilos rojos apoyados en el suelo rocoso, u otra fotografía que muestra un trozo de carne animal en manos de un joven o un grupo de cabezas de mujeres embarradas en actitud de oración. Si bien estas imágenes pueden remitir o no a un rito en particular, de alguna manera conducen al espectador a ese mundo mítico y lejano que lo atrapa y lo conduce a imaginar otra realidad [Ver Figuras 3 y 4 en Catálogo de Figuras en página 235].

Ligado a este concepto de lectura e interpretación de una imagen, Panofsky (1972) plantea que un aspecto fundamental para la comprensión de una obra, es tener en cuenta la significación intrínseca y los valores simbólicos y culturales que pueden estar representados a través de objetos, gestos o actos. Desde esta óptica es posible analizar las posturas corporales de muchos de los retratos que componen esta serie y vincularla con lo planteado anteriormente sobre los ritos. Las fotografías de Miles dejan a la vista una conexión de estos retratados con 'algo' que deja afuera al espectador. A través de la postura corporal de los indígenas -vinculado más al cielo que al acto fotográfico en sí- insinúa el acto de una persona en trance, y esto desemboca en un pensamiento ligado al rito y el mito.

En la obra de Sebastián Szyd esto también puede imaginarse, sea a través de la mirada de los indígenas retratados como también aquellas fotografías en donde el accionar de los protagonistas queda abierto a la interpretación de quien las observe. Una mujer apoyada sobre una pared, en la oscuridad; o un grupo de jóvenes a contraluz levantando un objeto hacia el cielo, en actitud de rezo o rito. La lectura del sentido y el vínculo con la 
realidad específica de estas culturas queda aquí a merced del espectador; quien desde un rol conciente o inconciente se deja atrapar por el significado mítico, ligado a estos pueblos originarios [Ver Figuras 5, 6 y 7 en Catálogo de Figuras en página 236].

\section{Conclusiones}

El trabajo fotográfico tanto de Miles como de Szyd resulta un aporte valioso a esta difícil tarea de dar voz a aquellos que la han perdido, en el tiempo y en el espacio. Las series fotográficas de ambos artistas revisan años y años de discriminación, desvalorización y silencio por parte de las comunidades indígenas.

La búsqueda de estas fotografías se posiciona cerca del respeto a la diversidad, mostrando una manera de encarar al 'otro' sin despreciar ni juzgar sus prácticas y costumbres. A la vez las imágenes buscan mostrar otra manera de encarar el paso del tiempo -distinto al que está acostumbrado el hombre de la cultura occidental-, presentando nuevos sentidos acerca de la vida y la muerte, nuevas concepciones sobre lo que es la felicidad y el amor por el prójimo. Pero por sobre todo, otra manera de ver y valorar la tierra, la naturaleza y el contacto con la vida espiritual.

Miles y Szyd han sabido rescatar a través de sus imágenes este enfoque tan particular acerca de la vida indígena y sus ideales. Cada uno con fotografías que apelan a cierto lenguaje estético y conceptual, muy diferentes entre sí. Se nota en ambos artistas esta capacidad por mostrar a los pueblos originarios desde ópticas distintas, pero que plantean un mismo significado intrínseco, ligado al respeto por la diversidad de ideas.

Las series fotográficas presentadas aportan una mirada constructiva sobre las comunidades relegadas en el territorio latinoamericano, invitando a reflexionar acerca del infinito y rico universo de creencias, concepciones y costumbres que el hombre moderno ha perdido frente a la vorágine del crecimiento tecnológico y el consumo desmedido e irreflexivo. Este texto propone tomar distancia y analizar los discursos escondidos -atrapados en el silencio- que se encuentran tras las poses y miradas de los retratados en ambas series fotográficas; aprendiendo a valorar todo aquello que tienen para mostrar y que hacen a su identidad cultural.

\section{Bibliografía}

Alonso, R. (2005). Quince x Quince. Fotógrafos x Críticos Buenos Aires: Fundación Praxis. Baigorria, O. y Swarinsky, M. (2002) Argentina: civilizados y excluídos. Bolivia: Asociación Latinoamericana de Investigadores de la Comunicación. En http://www.eca.usp.br

Barthes; R. (2009). Lo obvio y lo obtuso. Imágenes, gestos y voces. Bacelona: Paidós Comunicaciones.

Bauman, Z. (2006). Vida líquida. Buenos Aires: Paidós.

Billeter, E. (1993). Canto a la realidad. Fotografía Latinoamericana 1860-1993. Barcelona: Ed. Lunwerg. 
Butto, A. (s/f) "Las representaciones acerca del indio y el territorio en los expedicionarios de la Conquista del Desierto: discursos e imágenes de las campañas de 1879-1883”. Buenos Aires: Facultad de Filosofía y Letras, UBA / Asociación de Investigaciones Antropológicas. En http://congresobicentenario.webuda.com/files/simposio04_butto.pdf

Carlsen, L. (1999). "Autonomía indígena y usos y costumbres la innovación de la tradición http://www.ezln.org/revistachiapas/No7/ch7carlsen.html

Carrasco, M. (2000). Los derechos de los pueblos indígenas en Argentina. Buenos Aires: Editorial Vincinguerra SRL.

Eliade, M. (1994). Mito y realidad. Bogotá: Labor.

(1984) Mito del eterno retorno. Barcelona: Ariel.

García Salemi, A. C. (2011). La situación prehispánica y el avance sobra los pueblos originarios en el actual territorio argentino. Facultad de Agronomía y Zootecnia. Universidad Nacional de Tucumán.

Grünberg, Friedl Paz (2003). La relación de los indígenas con la naturaleza y los proyectos de Cooperación Internacional. Reflexiones sobre la práctica. Disponible en: http://guarani.roguata.com/articles/spa/gruenberg_relacion_indigena_naturaleza_2003.pdf

Kapuscinski, R. (2007). Encuentro con el otro. Barcelona: Anagrama.

Lévi-Strauss, C. (2000). (7a ed) Mitológicas IV: El hombre desnudo. México: Siglo Veintiuno Editores.

Llamazares, A. M. y Martínez Sarasola, C. (s/f) Reflejos de la cosmovisión originaria. Arte indígena y chamanismo en el Noroeste argentino prehispánico. Disponible en http://bit. ly/P6wi5T

López Austin, A. (1998). Los mitos del tlacuache. México:UNAM, IIA.

Maceira, M. R. (2011). El Estado argentino y los pueblos originarios. El respeto por la propiedad comunitaria en Revista electrónica del Instituto de Investigaciones "Ambrosio L. Gioja" Año V. Disponible en http://bit.ly/MksEBs

Olavarría, M. E. (1990). Análisis estructural de la mitología yaqui. México: INAH, UAM.

Panofsky, E. (1972). Estudios sobre iconología. Madrid: Alianza Editorial.

Sarasola Carlos Martínez (2011). (9 ed) Nuestros paisanos los indios. Vida, historia y destino de las comunidades indígenas en la Argentina, Buenos Aires: Editorial Nuevo Extremo. (2010). Identidad, cosmovisión y espiritualidad en los pueblos indígenas. Buenos Aires: Editorial Biblos.

Sarmiento, D. F. (1995). Civilización y Barbarie, Buenos Aires: Emecé.

Szyd, S. (2010) América. Buenos Aires: La Azotea.

Taipe Campos, N. (2004). Los mitos. Consensos, aproximaciones y distanciamientos teóricos, Gazeta de Antropología No 20. Disponible en http://bit.ly/Lvnoxo 


\section{Catálogo de Figuras}

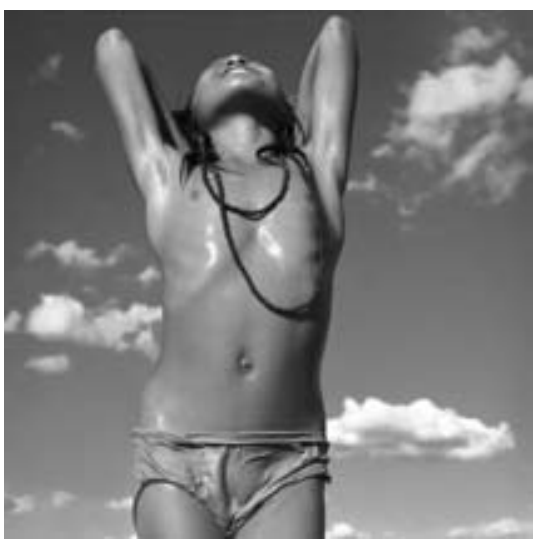

F1.

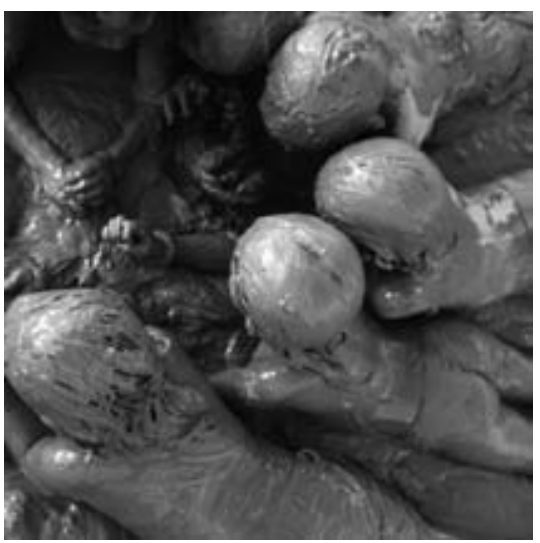

F3.

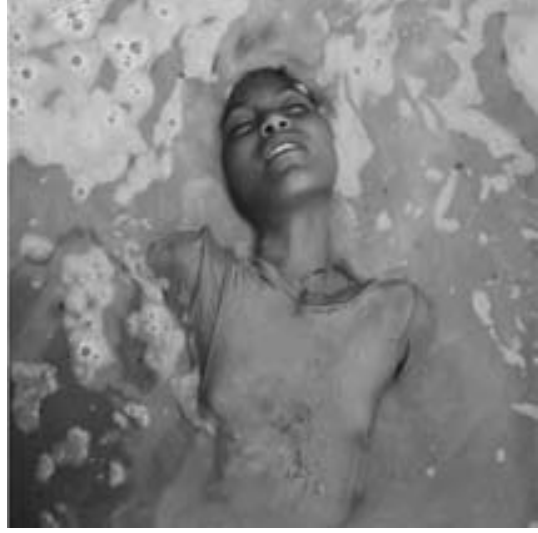

F2.

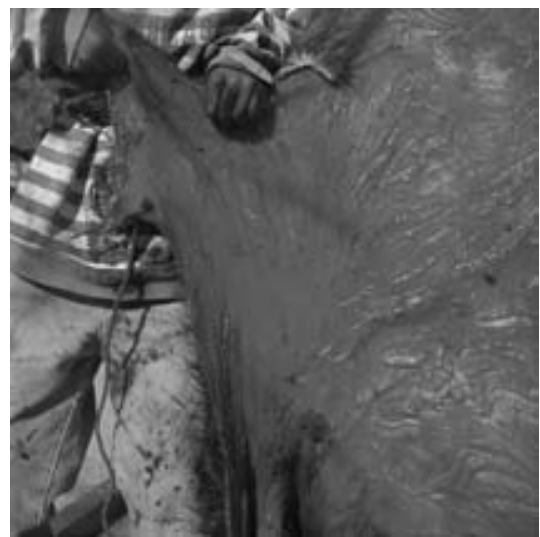

F4.

Figura. 1. Serie Chaco por Guadalupe Miles. Fuente. www.guadalupemiles.com.ar/o1.html Figura. 2. Serie Chaco por Guadalupe Miles. Fuente. www.guadalupemiles.com.ar/o11.html Figura 3. Serie Chaco por Guadalupe Miles. Fuente. www.guadalupemiles.com.ar/o4.html Figura 4. Serie Chaco por Guadalupe Miles. Fuente. www.guadalupemiles.com.ar/o7.html 


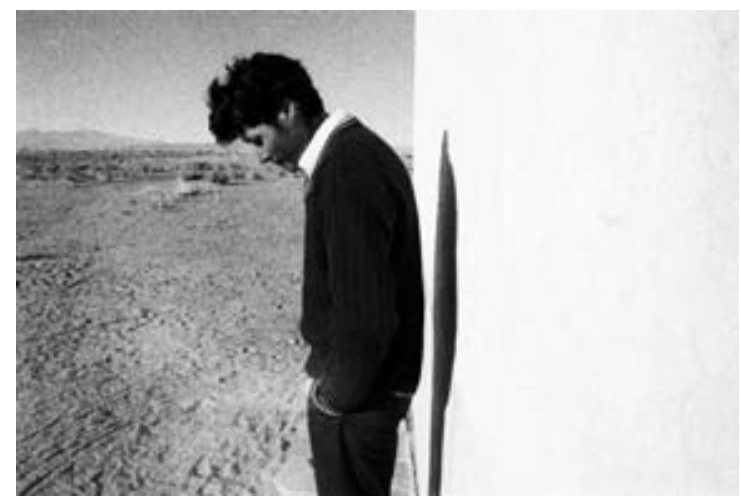

F5.

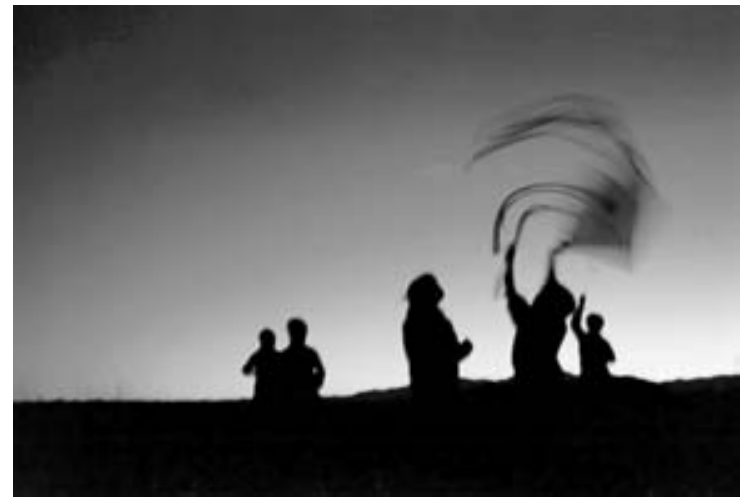

F6.

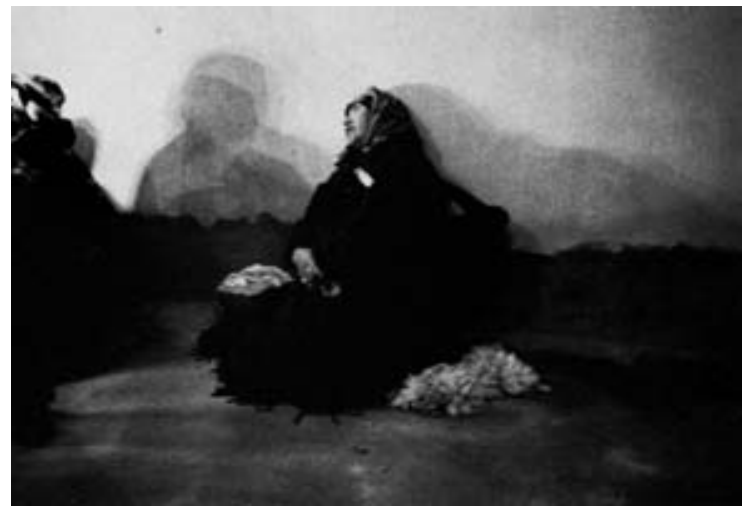

F7.

Figuras 5, 6. y 7. Sebastián Szyd. Fuente. Szyd, S. (2010). América. Buenos Aires: La Azotea. 
Summary: Argentina is characterized as a heterogeneous nation, with a large plurality of voices and cultures, in which the native communities voice is usually relegated. From the beginning the native peoples have to adjust themselves to the customs of the conquerors, but not lost their cultural identity, which still exists in its rites and ways of facing life.Many artists throughout Argentina's history, have been interested in portraying these customs and ideals. Painters and photographers have approached this work from the documentary and artistic fields, each from different approaches. Today in Argentina, the interest in the indigenous communities from the artistic field is ongoing.This paper proposes an approach to the work of two artists who have been able to show the life of indigenous communities in the north of the country from the standpoint of respect and admiration for these cultures. It examines the work of two contemporary Argentine photographers: Guadalupe Miles and Sebastián Szyd, who from their particular aesthetics and through their series Chaco and America have been involved personally with these cultures as part of their rites and customs. The text proposes to step back and analyze the hidden discourses -trapped in silence- that are behind the poses and look of those portrayed in both photographic series, learning to appreciate everything they have to show related to their cultural identity.

Keywords: Argentina - Art - contemporary - culture - diversity - equality - identity - imaginary - indigenous - Photography - respect - worldview.

Resumo: Argentina se caracteriza por ser uma nação heterogênea, com pluralidade de vozes e culturas, dentro das quais se encontra, relegada, a voz das comunidades indígenas. Desde um começo os povos originários se acomodaram aos usos e costumes dos conquistadores, mas não por isso perderam sua própria identidade cultural, que ainda perdura nos seus ritos e modos de encarar a vida.

Muitos artistas, ao longo da história argentina, se interessaram por retratar esses costumes e seus ideais. Pintores e fotógrafos encararam este trabalho desde o documental ou artístico, cada um desde enfoques e miradas diversas. Este interesse pelas comunidades indígenas dentro do campo artístico argentino continua ainda hoje presente.

Este artigo propõe uma aproximação ao trabalho de dois artistas que souberam mostrar a vida das comunidades indígenas no norte do país desde uma óptica de respeito e admiração por estas culturas. Analisa-se o trabalho de dois fotógrafos argentinos contemporâneos: Guadalupe Miles e Sebastian Szyd, os quais, cada um desde uma estética particular e através das suas séries Chaco e América respectivamente, se envolveram pessoalmente com estas culturas, fazendo parte dos seus ritos e costumes diárias.

O texto propõe tomar distancia e analisar os discursos escondidos -atrapalhados no silêncio- que se encontram trás as poses e miradas dos retratados em ambas as séries fotográficas, aprendendo a valorar tudo aquilo que têm para mostrar e que fazem a sua identidade cultural.

Palavras chave: Argentina - arte - contemporâneo - cosmovisão - cultura - diversidade fotografia - identidade - igualdade - imaginário - indígenas - respeito. 